\title{
Surgical removal of pterygium using amniotic membrane transplant mounted on freeze-dried fibrin glue - assessment of post-operative visual acuity, corneal endothelial cells density, pachymetry and recurrence
}

\author{
Maciej Kozak', Anna Wciślak' , Alina Bakunowicz-Łazarczyk², Urszula Szpakowicz', Ilona Pawlicka' \\ ${ }^{1}$ Regional Ophthalmic Hospital in Krakow, Poland \\ ${ }^{2}$ Pediatric Ophthalmology Department with Strabismus Treatment Center, Medical University of Bialystok Children's Clinical Hospital of Ludwik \\ Zamenhof, Bialystok, Poland
}

\begin{abstract}
Aims of the study were to assess the corneal parameters, visual acuity, and risk of recurrence after pterygium removal procedures involving amniotic membrane attachment to the scleral bed with freeze-dried fibrin glue and - on that basis - to evaluate the safety and therapeutic efficacy of the method.

Material and methods: The study involved a total of 27 patients. The inclusion criteria were the diagnosis of primary pterygium, absence of other ophthalmic disorders, and no history of eye injuries or ophthalmic surgery. The patients' corneal parameters (including pachymetry, corneal endothelial cell density) and visual acuity on days 7, 30 and 60 after the surgery were compared with corresponding baseline values in order to evaluate changes.

Results: Stable or improved visual acuity was demonstrated in all the subjects, with 26 patients achieving a BCVA of 1.0. The corneal endothelial cell population remained at a steady level in all the subjects, and none experienced a decline in cell density. Pachymetry showed
\end{abstract}

a slight variability during the period of follow-up, with an initial upward trend up until day 30 after the surgery ultimately followed by a return closer to the baseline value on day 60 postoperatively. None of the study participants reported any pain. Two recurrences of pterygium were noted during the follow-up period of 60 days.

Conclusions: The findings of the study show that the applied technique of pterygium removal with amniotic membrane transplantation using fibrin glue is associated with a low recurrence rate (7.4\%), absence of postoperative pain, stability or improvement of visual acuity, a consistent level of corneal endothelial cell population, and stable pachymetry values. Based on these outcomes, the method appears to be an effective and safe technique of pterygium removal. However, in view of the small size of the study group and the short postoperative follow-up period, further studies are needed to obtain more definite results.

KEY WORDS: pterygium, fibrin glue, recurrent pterygium, amniotic membrane

\section{INTRODUCTION}

Pterygium refers to abnormal overgrowth of conjunctival fibrovascular tissue. It tends to grow into the cornea, impairing visual acuity by inducing astigmatism, and in severe cases, it may encroach the pupil and directly occlude the optical axis [1].

The etiology and pathogenesis of pterygium are not fully elucidated. The factors known to induce the condition include exposure to UV light, dust and dirt, as well as dry eye syndrome, and old age $[1,2]$.

The primary mode of management is surgery. There are many techniques to remove pterygium surgically, ranging from simple excision leaving the sclera exposed to removal followed by filling the defect with a conjunctival autograft or amniotic membrane with the use of sutures or tissue glue [3-6]. There are multiple variants of these procedures, such as P.E.R.F.E.C.T. (pterygium extended removal followed by extended conjunctival transplantation) or CLAG (conjunctival limbal autograft). In the scientific literature, there is no consensus as to which of the techniques of surgical pterygium removal is the best because some of the procedures are still associated with a high risk of recurrence. Based on the available reports, the risk of recurrence after using the technique 
of amniotic membrane transplantation ranges from $3.8 \%$ to $40.9 \%[4,6]$. On the other hand, a study conducted by Hirst demonstrates that P.E.R.F.E.C.T. is a method associated with a practically zero recurrence rate $(0.01 \%)$ [7]. Other complications of the procedure include scarring and pterygiuminduced astigmatism persisting after surgery.

One of the newer surgical methods involves pterygium excision followed by the placement of an amniotic membrane graft using freeze-dried fibrin glue.

Amniotic membrane has long been known and used for therapeutic purposes not only in ophthalmology but also in dermatology, plastic surgery or otolaryngology. It is harvested from the placenta during Cesarean section. To reduce the risk of transmission of infection, donor blood is always tested for infectious diseases. Since amniotic membrane is an avascular tissue and does not produce antigens of histocompatibility (HLA-A, HLA-B, HLA DR), it is well tolerated, with no rejections. The amniotic membrane transplant dissolves spontaneously, usually within 1 to 2 weeks. Based on its anti-inflammatory and antiangiogenic properties, and the ability to accelerate epithelialization and tissue regeneration, amniotic membrane has a wide range of applications. In ophthalmology, it is used in the treatment of corneal ulceration, neurotrophic keratopathy, corneal perforation, as well as in pterygium removal procedures $[8,9]$.

Despite being employed in surgery for several years now, tissue glue used to have only limited applications in microsurgery on account of the complicated preparation procedure. The introduction of freeze-dried fibrin glue has significantly streamlined the process, extending the range of potential uses.

Tisseel, the fibrin glue used in the study, is produced from human plasma and contains, among other ingredients, fibrinogen, aprotinin and thrombin. Being a biological material, the glue carries the risk of transmitting viruses and infectious agents undetected by routine testing, as well as inducing hypersensitivity reactions in patients [10-12]. During the preparation of blood products, plasma is tested for pathogens (viruses, bacteria), but certain problems remain including serological windows, potential laboratory errors, and microorganisms that are not yet known.

Despite these potential risks, fibrin-based adhesives are gaining importance because of their biological properties and biodegradability. Various types of tissue glue are used in conjunctival autografts, contributing to shorter healing times and reduced postoperative complaints $[3,10,12-14]$.

Based on the available publications evaluating sutureless and sutured procedures, it is not possible to resolve conclusively which technique carries a lower risk of recurrence [10, 15-17]. However, it is not without significance that the use of glue instead of traditional sutures offers an opportunity to reduce the duration of the procedure and improves the postoperative comfort of patients $[10,18]$.

\section{MATERIAL AND METHODS}

The study was conducted at the Provincial Ophthalmic Hospital in Krakow, Poland. A total of 27 patients ( 9 women and 18 men) aged 33 to 79 years were enrolled. The pterygi- um was completely excised, and the amniotic membrane was transplanted using freeze-dried tissue glue for fixation. Pterygium removal involved scleral debridement and excision of the Tenon capsule. The two components of the fibrin glue were applied using separate syringes directly to the scleral bed. A previously adjusted amniotic membrane transplant was then placed on the glue.

The study inclusion criteria were the diagnosis of primary pterygium, absence of other ophthalmic disorders, and no history of eye injuries or ophthalmic surgery. Pterygium was evaluated using Kanski's grading system [19]:

- grade 1 - the lesions encroach the cornea for a distance of less than $2 \mathrm{~mm}$ beyond the limbus;

- grade 2 - the degeneration involves up to $4 \mathrm{~mm}$ of the cornea beyond the limbus;

- grade 3 - the lesions encroach the cornea for a distance of more than $4 \mathrm{~mm}$ beyond the limbus and lie directly in the line of vision.

The study subjects were diagnosed with grade 2 and 3 pterygium according to the above grading system.

At baseline, the patients were evaluated to determine visual acuity, total refraction, keratometric and pachymetric parameters, and the density of corneal endothelial cells. Statistical analysis was performed with Pearson's, Student's $t$ and ANOVA tests, with the level of statistical significance set at $p<0.05$. Additionally, the analysis included the subjective postoperative symptoms reported by the patients, and the pterygium recurrence rate. The parameters were assessed at baseline (day 0), and subsequently on days 7, 30 and 60 after surgery. The present article reports on the analysis of visual acuity, corneal endothelial cell population, and pachymetry values.

\section{RESULTS}

\section{Assessment of visual acuity}

Visual acuity was measured using standard Snellen charts. The mean baseline BCVA (best corrected visual acuity) in all the subjects was 0.92 , and it was slightly higher in women (0.94) than in men (0.91). Both in women and men, the value of BCVA tended to increase as early as on the postoperative day 7 , reaching 1.0 on day 60 after the surgery (Figure 1). One exception was a male patient whose baseline BCVA was 0.6 ,

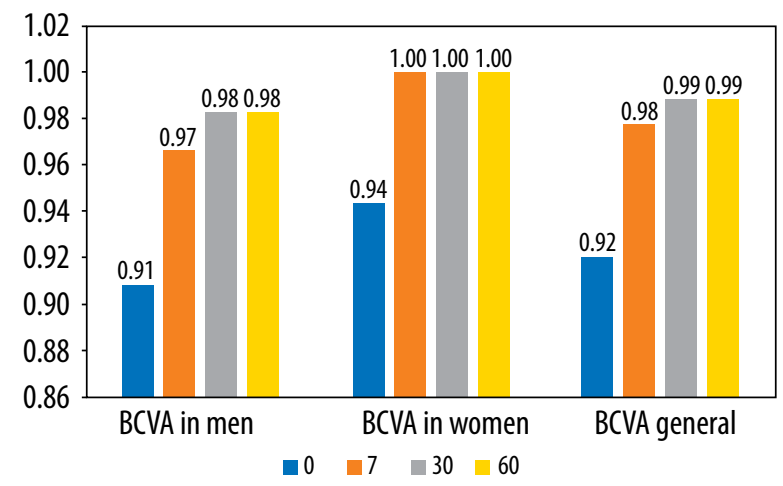

Figure 1. BCVA evaluation in women and men 
and improved to 0.7 on the postoperative day 60 . The patient with the lowest baseline BCVA in the study - 0.16 , achieved the value of 1.0 on day 60 after the procedure (Table I).

In the group of patients with baseline BCVA $=1.0$, visual acuity remained stable throughout the entire follow-up period, while in the group with baseline BCVA $<1.0$, there was a statistically significant improvement in the parameter (Tables I and II).

\section{Evaluation of corneal endothelial cells}

Corneal endothelial cells (ECs) play a very important role in maintaining proper hydration of the cornea, thus contributing to corneal transparency. Low endothelial cell density may lead to corneal decompensation, edema and, consequently, visual acuity impairment.

Within the study, the stability of EC populations after pterygium surgery was evaluated. Even though ECs form the innermost layer of the cornea, their function may become impaired. During the surgery, the corneal epithelium is partially removed, exposing the substantia propria, through which substances used during the procedure are able to penetrate, potentially damaging the EC layer. There are recent reports on cases of reduced EC populations after pterygium surgery performed with mitomycin C [20].

In the study group, the mean density of endothelial cells before surgery was $2,231 / \mathrm{mm}^{2}$, with the lowest value being $1,896 / \mathrm{mm}^{2}$.

Table I. BCVA assessment in the group with baseline $B C V A<1.0$ depending on the time elapsed after surgery

\begin{tabular}{|l|c|c|c|c|c|}
\hline Sex & Age (years) & OBCVA & 7BCVA & 30BCVA & 60BCVA \\
\hline M & 55 & 0.9 & 1.0 & 1.0 & 1.0 \\
\hline M & 57 & 0.16 & 0.8 & 1.0 & 1.0 \\
\hline M & 62 & 0.7 & 1.0 & 1.0 & 1.0 \\
\hline M & 64 & 0.6 & 0.6 & 0.7 & 0.7 \\
\hline F & 62 & 0.9 & 1.0 & 1.0 & 1.0 \\
\hline F & 65 & 0.9 & 1.0 & 1.0 & 1.0 \\
\hline F & 68 & 0.7 & 1.0 & 1.0 & 1.0 \\
\hline
\end{tabular}

$O B C V A$ - visual acuity before surgery. $7 B C V A$ - visual acuity on the postoperative day 7. $30 B C V A$ - visual acuity on the postoperative day 30.60BCVA - visual acuity on the postoperative day 60

Table II. Evaluation of significance of BCVA improvement in patients with baseline $B C V A<1.0$

\begin{tabular}{|l|c|c|}
\hline \multirow{2}{*}{ BCVA } & \multicolumn{2}{|c|}{ Number of subjects } \\
\cline { 2 - 3 } & $\begin{array}{c}\text { Baseline } \\
\text { value }\end{array}$ & Final value \\
\hline Baseline $=1.0$ & 20 & 20 \\
\hline Baseline $<1.0$ & 7 & 1 \\
\hline Mean for baseline values $<1.0$ & 0.70 & 0.96 \\
\hline$t$ test for means & $t=2.56$ & $p=0.021$ \\
\hline
\end{tabular}

During the follow-up examinations, cell density was shown to be at a stable or even slightly elevated level (Figure 2). Endothelial cells are unable to regenerate and divide, so the increase in their density observed in the study is probably due to higher corneal transparency after surgery and, as a result, better accessibility of the inner layers of the cornea to specular microscopic evaluation.

The mean value of endothelial cell density on day 60 after the procedure was $2,360 \mathrm{~mm}^{2}$. The EC population was not shown to be reduced in any of the study subjects.

The above findings demonstrate the safety of the surgical technique for the population of corneal endothelial cells.

\section{Pachymetry}

The thickness of the cornea was measured in its central part using a specular microscope. During pterygium surgery, the corneal epithelium was partially removed, which could have affected the pachymetry value. The results of measurements of corneal thickness performed on day 0 (immediately before the procedure) and on the postoperative days 7, 30 and 60 were compared.

As shown in Table III, the mean pachymetry values were stable throughout the entire follow-up period, and the final value was slightly higher than the baseline value. The most prominent changes were recorded on day 30 , when both the postoperative minimum $(516 \mu \mathrm{m})$ and maximum $(742 \mu \mathrm{m})$ values were achieved. The maximum value of $742 \mu \mathrm{m}$ was not related to major pachymetric changes or a pathological process in the cornea, but to the baseline value which was $728 \mu \mathrm{m}$.

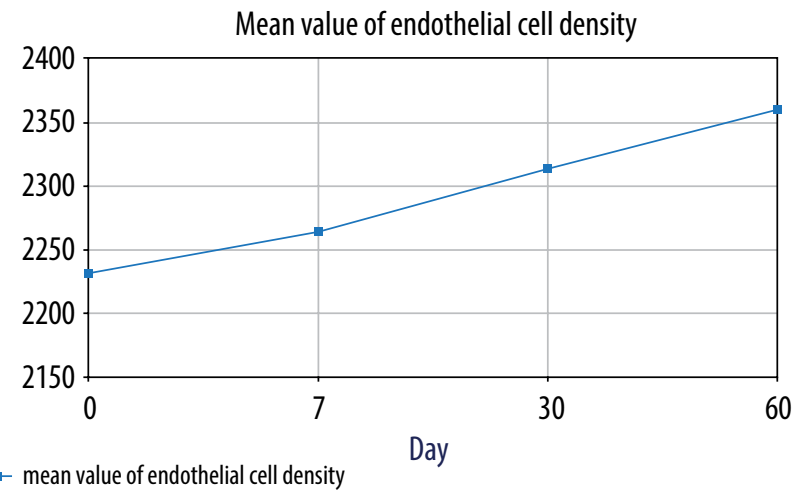

Figure 2. Changes in mean EC values on different days of analysis [amount $/ \mathrm{mm}^{2}$ ]

Table III. Dynamics of changes in the mean pachymetry value for the right and left eyes (in $\mu \mathrm{m}$ )

\begin{tabular}{|l|c|c|c|c|c|}
\hline \multirow{2}{*}{ Pachymetry } & \multicolumn{4}{|c|}{ Day } & \multirow{2}{*}{ Mean } \\
\cline { 2 - 5 } & $\mathbf{0}$ & 7 & 30 & 60 & \\
\hline Right eye & 562.74 & 564.59 & 569.85 & 564.15 & 565.33 \\
\hline Left eye & 562.52 & 564.52 & 570.72 & 565.12 & 565.72 \\
\hline Mean & 562.63 & 564.56 & 570.29 & 564.63 & 565.53 \\
\hline
\end{tabular}


The mean pachymetry value increased until day 30 after the surgery, reaching $570.29 \mu \mathrm{m}$. However, on day 60 , the value dropped to $564.63 \mu \mathrm{m}$, reaching a similar level to the baseline (Figure 3). The overall mean corneal thickness throughout the study period was $565.53 \mu \mathrm{m}$. A general analysis taking into account the sex of the study subjects reveals no significant correlations (Table IV).

\section{Pain and recurrence}

Pain and recurrence are among common complications after pterygium surgery. Pain and discomfort are often due to the sutures causing eye irritation. None of the patients in the study group reported pain, and only 2 participants stated they occasionally felt a stinging sensation and discomfort around the postoperative wound. However, the symptoms were not as severe as to require treatment with topical or oral analgesics. Throughout the entire follow-up period, the patients denied any pain in the postoperative wound area, and reported no need for analgesic medications.

Over the 60-day follow-up, pterygium recurrence was noted in 2 patients. It was not found to correlate with the patients' sex or age. The condition recurred in a 50-year-old man and a 65 -year-old woman. Since only $7.4 \%$ of all the subjects experienced a recurrence, there is good reason to presume that fibrin glue is an effective solution in pterygium surgery.

\section{DISCUSSION}

The main treatment of pterygium is surgery. There are many surgical techniques for pterygium removal, but no gold standard has as yet been established. In addition, there is no consensus in the available literature as to whether sutureless or suture techniques are superior. There are both publications about the beneficial effects of tissue glue, lowering the risk of pterygium recurrence, and opposite reports [10, 15-17].

The risk of pterygium recurrence after surgery with amniotic membrane transplantation varies from $3.8 \%$ to $40.9 \%$ $[4,6]$. The low risk of recurrence obtained in the present study (7.4\%) suggests that the surgical technique involving the use of amniotic membrane and freeze-dried fibrin glue is highly

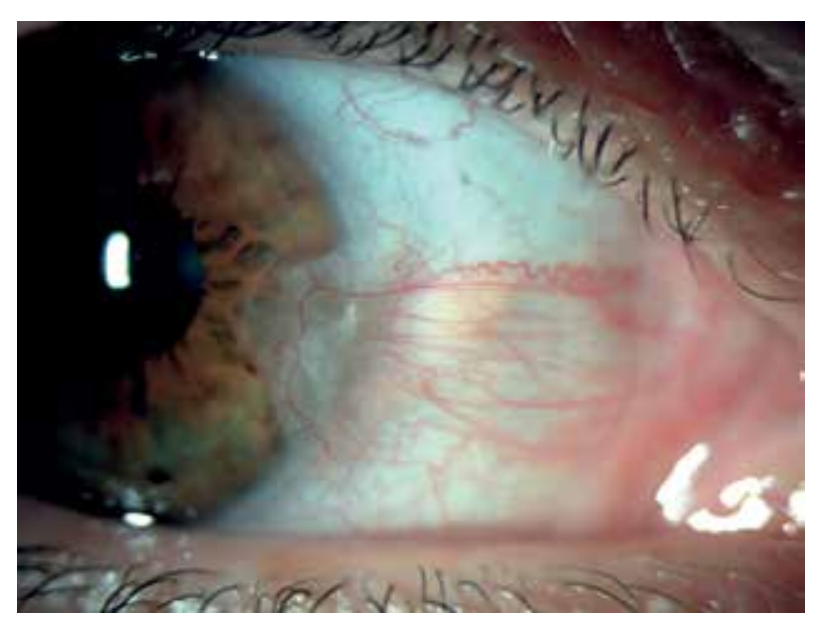

Figure 4. Pterygium in a 61-year-old woman before surgery

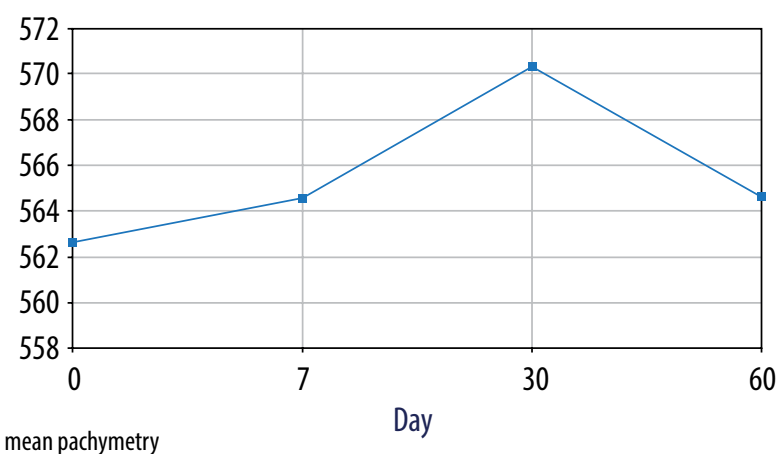

Figure 3. Changes in mean pachymetry values on different days of analysis [ $\mu \mathrm{m}]$

Table IV. Evaluation of the significance of differences in the mean pachymetry values by sex

\begin{tabular}{|l|c|c|c|}
\multirow{2}{*}{ Day of study } & \multicolumn{2}{|c|}{ Sex } & \multirow{2}{*}{ p for $t$ test } \\
\cline { 2 - 3 } & F & M & \\
\hline OP $(\mu \mathrm{m})$ & 546.667 & 570.778 & 0.128 \\
\hline $7 P(\mu \mathrm{m})$ & 550.444 & 571.667 & 0.130 \\
\hline $30 \mathrm{P}(\mu \mathrm{m})$ & 553.556 & 578.000 & 0.102 \\
\hline $60 \mathrm{P}(\mu \mathrm{m})$ & 551.556 & 570.444 & 0.176 \\
\hline
\end{tabular}

OP - pachymetry value at baseline; $7 P$ - pachymetry value on the postoperative day 7; $30 P$ - pachymetry value on the postoperative day $30 ; 60 \mathrm{P}$ - pachymetry value on the postoperative day 60

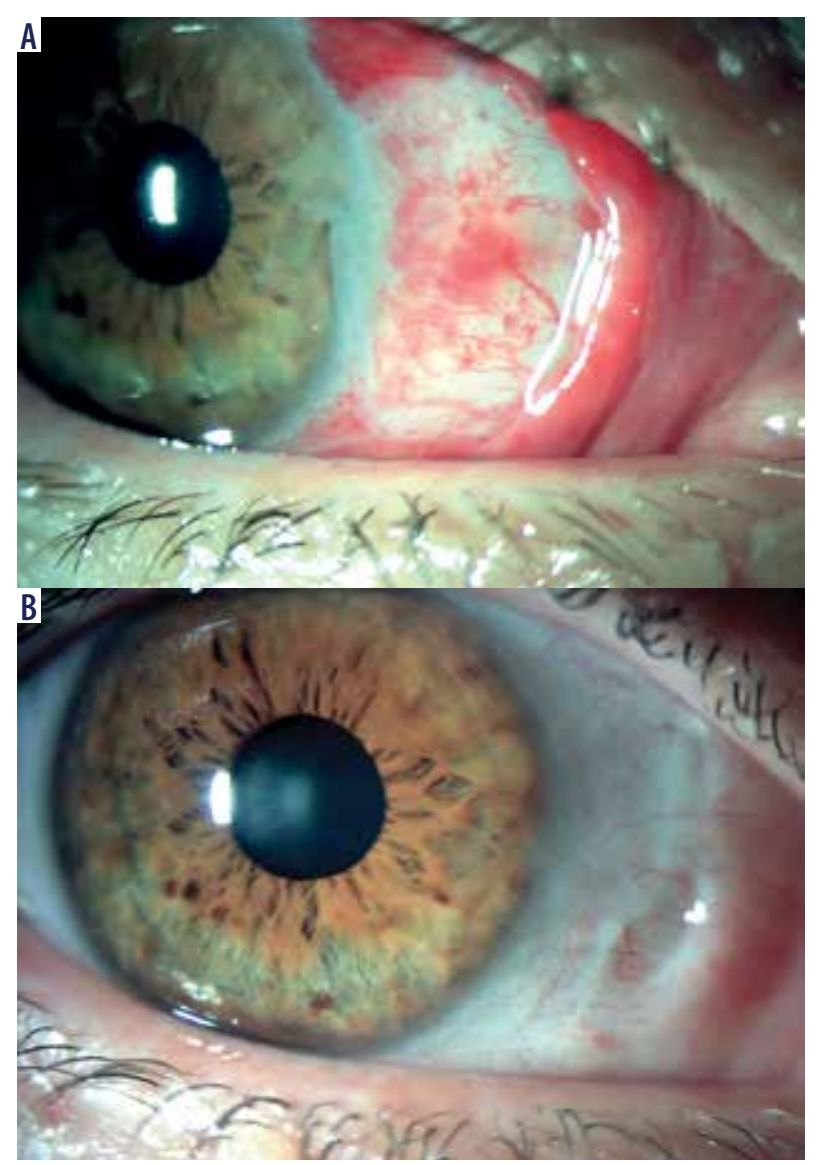

Figure 5. Photographs of the same patient on days 1 and 60 after the procedure 
effective. It is still debatable whether a conjunctival autograft or amniotic membrane transplant to cover the exposed bed after pterygium excision is a more effective treatment modality [21]. Both surgical methods are used in a complementary and parallel manner depending on the operating conditions. It is not uncommon that conjunctival scarring or the effects of eye surgery (e.g. after surgical treatment for glaucoma) make it impossible to obtain a sufficiently large conjunctival graft to cover the exposed pterygium bed. In such cases, the application of amniotic membrane is necessary.

The study included an analysis of changes in BCVA during the follow-up period. In the group of patients with baseline $\mathrm{BCVA}=1.0$, visual acuity remained stable in the entire follow-up period, while in the group with baseline BCVA < 1.0, there was a statistically significant improvement in the parameter. No deterioration in visual acuity was observed in any of the study subjects. An analysis conducted by Tłustochowicz [3] to compare three techniques of pterygium surgery showed an improvement in best corrected visual acuity in patients treated by all surgical methods, but a statistically significant improvement was observed only in patients undergoing amniotic membrane fixation using fibrin glue.

The available publications indicate that the baseline endothelial cell density in pterygium-affected eyes is reduced [22, 23], which is attributable to long-term exposure to UV light [22]. Consequently, endothelial protection is always a major concern in ophthalmic surgical procedures. In the reported study, postoperative endothelial cell density remained at a steady level, and no decrease was observed in any patient.

The available literature includes a number of publications analyzing pachymetry changes after cataract surgery [24], but there are few detailed reports on patients undergoing pterygi- um removal surgery. Following cataract phacoemulsification, a post-surgical increase in pachymetry values is observed, with a return to the baseline levels occurring approximately 30 days postoperatively. The findings of the study show that after pterygium surgery, the pachymetry values increased until day 30 , and a return to baseline values occurred around the postoperative day 60 .

\section{CONCLUSIONS}

Surgical removal of pterygium followed by transplantation of amniotic membrane mounted on freeze-dried tissue glue is an effective method of treatment. The application of fibrin glue has a positive effect on the healing process and reduces the patient's postoperative discomfort.

In patients with baseline BCVA $<1.0$, a statistically significant improvement in visual acuity was achieved, and in patients with $B C V A=1.0$, visual acuity was stable throughout the entire follow-up period.

Also, the endothelial cell population was found to be stable, with no decrease in EC density observed in any of the subjects.

The pachymetry values displayed a slight rising tendency until day 30 after the surgery, and returned to the baseline levels on the postoperative day 60 .

Based on the study outcomes, the method appears as an effective and safe technique of pterygium removal. However, in view of the small size of the study group and the short postoperative follow-up period, further studies are needed to obtain more definite results.

\section{DISCLOSURE}

The authors declare no conflict of interest.

\section{References}

1. Bowling B, Kanski J. Okulistyka kliniczna. Edra Urban \& Partner, Wrocław 2017; 162-164.

2. Jawor M, Wyględowska-Promieńska D. Skrzydlik - aktualne spojrzenie na patogenezę oraz leczenie. Klinika 0czna 2019; 1: 59-61.

3. Tłustochowicz M, Krix-Jachym K, Byszewska A, Rękas M. Analiza zmian astygmatyzmu rogówkowego - porównanie trzech metod usunięcia skrzydlika. Klinika Oczna 2018; 2: 80-84.

4. Nuzzi R, Tridico F. How to minimize pterygium recurrence rates: clinical perspectives. Clin Ophthalom 2018; 12: $2347-2362$.

5. Tejsu M, Jing J, Kai H. Clinical outcome of combined conjunctival autograft transplantation and amniotic membrane transplantation in pterygium surgery. Int J Ophthalmol 2018; 11: 395-400.

6. Lee JS, Ha SW, Yu S, et al. Efficacy and safety of large conjunictival autograft for recurrent pterygium. Korean J 0phthalom 2017; 31: 469-478.

7. Hirst LW. Recurrence and complications after 1,000 surgeries using pterygium extended removal followed by extended conjunctival transplant. Ophthalmology 2012; 119: 2205-2210.

8. Jirsova K, Jones GLA. Amniotic membrane in ophthalmology: properties, preparation, storage and indications for grafting-a review. Cell Tissue Bank 2017; 18: 193-204.

9. Peric Z, Skegro I, Durakovic N, et al. Amniotic membrane transplantation-a new approach to crossing the HLA barriers in the treatment of refractory ocular graft-versus-host disease. Bone Marrow Transplant 2018; 53: 1466-1469.

10. Wadgaonkar SP, Tiwari RR, Patil PA, Kamble BS. Fibrin glue versus suture technique for pterygium excision: a prospective study in tertiary-based rural hospital. J Clin Ophthalmol Res 2017; 5: 23-27.

11. Noori A, Ashrafi SJ, Vaez-Ghaemi R, et al. A review of fibrin and fibrin composites for bone tissue engineering. Int J Nanomedicine 2017; 12: 4937-4961.

12. Sheppard JD, Mansur A, Comstock TL, Hovanesian JA. An update on the surgical management of pterygium and the role of the loteprednol etabonate ointment. Clin Ophthalmol 2014, 8: 1105-1118.

13. Bhatia J, Varghese M, Narayanadas B, Bhatia A. Cut-and-place technique of pterygium excision with autograft without using sutures or glue: Our experience. Oman J Ophthalmol 2017; 10: 81-86.

14. Halil H, Gökçen G, Alper M, et al. Non-recurrence complications of fibrin glue use in pterygium surgery: prevention and management. Open Ophthalmol J 2015; 9: 159-163. 
15. Karalezli A, Kucukerdonmez C, Akova YA, et al. Fibrin glue versus sutures for conjunctival autografting in pterygium surgery: A prospective comparative study. Br J Ophthalmol 2008; 92: 1206-1210.

16. Koranyi G, Seregard S, Kopp ED. The cut-and-paste method for primary pterygium surgery: Long-term follow-up. Acta Ophthalmol Scand 2005; 83: 298-301.

17. Bahar I, Weinberger D, Gaton DD, Avisar R. Fibrin glue versus vicryl sutures for primary conjunctival closure in pterygium surgery: Long-term results. Curr Eye Res 2007; 32: 399-405.

18. Singh SK. Pterygium: epidemiology prevention and treatment. Community Eye Health 2017, 30: S5-S6.

19. Kański JJ. Okulistyka kliniczna. Elsevier, Wrocław 2007.

20. Avisar R, Apel I, Avisar I, Weinberger D. Endothelial cell loss during pterygium surgery: importance of timing of mitomycin C application. Cornea 2009; 28: 879-881.

21. Clearfield E, Hawkins BS, Kuo IC. Conjunctival autograft versus amniotic membrane transplantation for treatment of pterygium: findings from a Cochrane systematic review. Am J Ophthalmol 2017; 182: 8-17.

22. Li X, Dai Y, Xu W, Xu J. Essential role of ultraviolet radiation in the decrease of corneal endothelial cell density caused by pterygium. Eye (Lond) 2018; 32: 1886-1892.

23. Sousa HCC, Silva LNP, Tzelikis PF. Corneal endothelial cell density and pterygium: a cross-sectional study. Arq Bras Oftalmol 2017; 80:317-320

24. Kongsap P. Central corneal thickness changes following manual small incision cataract surgery versus phacoemulsification for white cataract. Rom J Ophthalmol 2019; 63: 61-67. 